\title{
A descriptive study on Hayman suture technique to control postpartum hemorrhage
}

\author{
Anamika Majumdar ${ }^{1}$, Kallol Mallick², Bipin Vasava², Kanan T Desai ${ }^{3}$, Malati Dalal ${ }^{4}$ \\ Sri Lanka Journal of Obstetrics and Gynaecology 2012; 34: 79-83
}

\begin{abstract}
Objective: To conduct a descriptive study on Hayman suture technique to control postpartum hemorrhage

Method: Hayman suture was applied in 43 cases. A No-1 Vicryl suture was used on a round body or a straight needle. In 36 cases $(83.72 \%)$ Hayman suture was the only intervention. In 4 cases $(9.30 \%)$ uterine vessels and ovarian vessels were also ligated along with Hayman suture. In 3 cases (7\%), along with Hayman suture, Gunasheila's circumferential sutures were taken.
\end{abstract}

Results: None of the 43 patients required hysterectomy.

Conclusion: Hayman suture technique is an easily and rapidly applied, effective, simple, safe, life saving and fertility preserving method to control atonic postpartum hemorrhage.

Keywords: atonic post partum hemorrhage, Hayman suture, B-Lynch suture

\section{Introduction}

It has been estimated that worldwide over 125,000 women die of postpartum hemorrhage (PPH) each year ${ }^{1}$. PPH complicates approximately $3.7 \%$ of vaginal and $6.4 \%$ of caesarean delivery ${ }^{2}$. In India $25.6 \%$ of maternal deaths are due to hemorrhage ${ }^{3}$. Uterine atony accounts for $75 \%-90 \%$ of primary $\mathrm{PPH}^{4}$. The traditional management of this condition begins

${ }^{1}$ Assistant Professor, Department of Obstetrics and Gynaecology,

2 Assistant Professor, Department of Community Medicine,

3 Postgraduate resident, Department of Community Medicine,

${ }^{4}$ Professor and Head, Department of Obstetrics and Gynaecology, Surat Municipal Institute of Medical Education and Research (SMIMER), Surat, India.

Correspondence: Anamika Majumdar

E-mail: anamikakallol@yahoo.com with conservative methods such as bimanual compression, medical therapy with uterotonic agents, uterine temponade with balloons and occasionally arterial embolisation ${ }^{5}$; the failure of which often mandates surgical intervention. Surgical measures such as ligation of the major pelvic vessels demand a rarely used skill possessed by few registrars. In the event of intractable hemorrhage despite the above measures hysterectomy is usually the final resort.

In 1997 Christopher B-Lynch devised an innovative technique to treat uterine atony where a continuous suture was used to envelop and mechanically compress the uterus in an attempt to avoid hystrectomy ${ }^{5}$. Hayman suture, the modification of B-Lynch suture, offers the potential advantage that it can be applied faster and easier, avoiding the performance of a lower segment hysterectomy, when PPH follows a vaginal delivery ${ }^{6}$.

The aim of our study is to review the cases and their outcomes in our institution, in which atonic PPH was not controlled with the available drugs (uterotonics) and where fertility preserving Hayman sutures were applied over highly skillful obstetric hysterectomy.

\section{Materials and methods}

A retrospective study of all women who delivered between April, 2007 and March, 2010 was collected from our departmental database. Primary $\mathrm{PPH}$ is defined as a blood loss of more than $500 \mathrm{ml}$ at or within 24 hours of delivery. There were a total of 18,750 deliveries during this period, with primary $\mathrm{PPH}$ occurring in 938 of these cases. Blood loss of $500 \mathrm{ml}$ or more was determined by visual inspection by the attending obstetrician which was a subjective judgment. Out of the 938 cases of PPH, 734 (78.25\%) cases were of PPH due to uterine atony. Uterine atony was determined by abdominal palpation of uterus. In Atonic PPH uterus is soft in contrast to traumatic PPH where uterus is firm, followed by bimanual examination under anesthesia. Additionally before proceeding for Hayman suture, per vaginal examination was done under anesthesia to rule out 
evidence of trauma. Patient's record was also examined to rule out any pre existent coagulopathy.

The Hayman suture procedure was performed in 43 cases only after uterine atony did not respond to measures such as uterine massage, bimanual compression and the use of uterotonics, i.e. Oxytocin, Ergometrine, PG-F2a, Misoprostol. Out of these 43 cases, 38 cases were delivered in our Institute and five cases were referred from other hospitals. The need for hysterectomy was avoided in all the cases. Uterine and ovarian vessel ligation was done in four cases and Gunashila's universal circumferential sutures were taken in three cases in addition to Hayman suture. It is believed that the ideal suture should be strong, monofilament (to minimize possible trauma to the friable tissue of the atonic uterus), quickly absorbed, and mounted on a large curved or on a straight needle. Ideally the suture needs to maintain the tensile strength for 48-72 hours. In our series of 43 cases the procedure was done with Vicryl No-1 (Polyglactin) in all the cases.

The procedure for Hayman suture technique was as follows:

1. The patient was given appropriate anesthesia and catheterized.

2. The abdomen was opened by an appropriate sized incision or if the patient had a caesarean section the same incision.

3. On entering the abdomen the uterus was exteriorized and rechecked to identify any bleeding point. If bleeding was diffuse as in uterine atony and coagulopathy or profuse placental bleeding where no obvious bleeding point is observed, then bimanual compression was first applied to assess the potential chances of success of the Hayman suturing technique. The vagina was swabbed to confirm adequate control of the bleeding.

4. If the vaginal bleeding was controlled, a straight needle or a curved needle is used to transfix the uterus from front to back, just above the reflection of the bladder and is then tied at the fundus of the uterus. This can be done as one suture on each side of the uterus or more than one suture if uterus is particularly broad ${ }^{7}$.

Figure 1 shows the photograph of Hayman suture taken in a case of atonic PPH.

Post procedure the patients were discharged after seven days. Till date all patients were examined daily by the Obstetrician's team on daily round of the ward. After that patients were called on the follow-up initially weekly for first six weeks and later monthly up to six months. No reminder to the patients was given for the follow-up visits. In the follow-up visits women were interviewed and examined for any complications and side-effects by obstetricians. No deliberate follow-up was made later than six months except that the note on the women returning with the subsequent pregnancies to the Institute from the cohort was kept up till December, 2011.

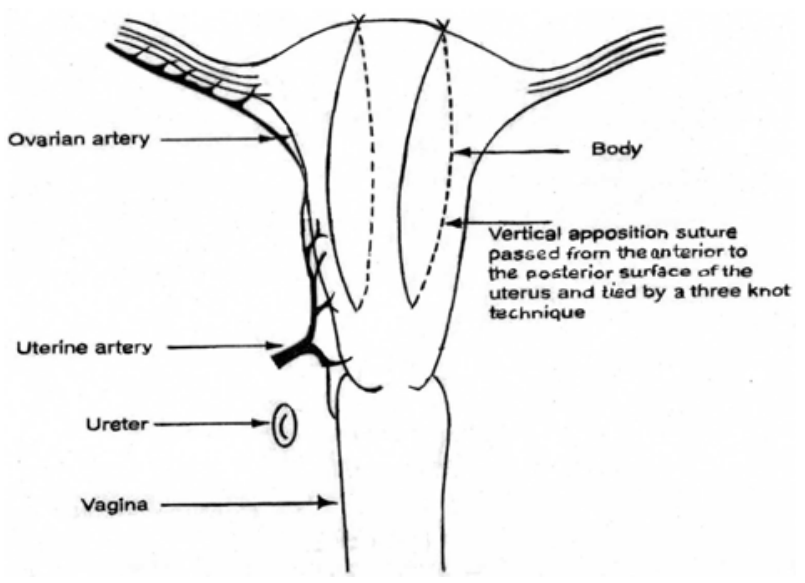

Figure 1. Hayman suture taken in a case of atonic PPH

\section{Results}

Hayman suture was applied in 43 cases of total $938 \mathrm{PPH}$ patients. Type of intervention is as given in Table 1. In 36 patients Hayman sutures alone were taken. In rest of the seven patients additional methods like ligating uterine artery and ovarian artery (in 4 patients) and Gunasheilla's universal sutures were taken (in 3 patients). Time of application can also be seen from Table 1. Age distribution of women is shown in Table 2; majority of the patients were in the age group of 20-25yrs. Gestational weeks of women is in Table 2 and most of the pregnancy were term pregnancy. Mode of delivery of women is as in Table 2; out of 43 patients in whom Hayman suture was applied, 34 were delivered by LSCS. Numbers of primary cases is given in Table 2; nine patients out of 43 were referred from outside.

Follow up of the patients was as per Table 3. Out of total patients all were followed up to seven days, 33 were followed up to six weeks and only 28 were followed up to six months. Rest of the patients stopped coming for follow-up visits and could not be traced hence their outcome was not known. Also important is that out of the 43 initial patients, 14 became pregnant and came to the Institute, of which five delivered subsequently in the Institute in follow up till December 2011. Those women who might have become pregnant and visited other hospitals could not be traced. 
Table 1. Hayman's suture application

\begin{tabular}{lcc}
\hline Parameter & Number $(n=43)$ & Percentage \\
\hline Time taken to apply the Hayman suture from the time of detecting the PPH & & $6.98 \%$ \\
$<10$ minutes & 35 & $81.40 \%$ \\
11 to 20 minutes & 5 & $11.63 \%$ \\
$>20$ minutes & 36 & $83.7 \%$ \\
Type of intervention & 4 & $9.3 \%$ \\
Hayman suture & & $7 \%$ \\
Hayman suture + (Ovarian + Uterine) vessel ligation & 3 & $7 \%$ \\
Hayman suture + (Ovarian + Uterine) vessel ligation & & \\
\hline
\end{tabular}

Table 2. Profile of patients

\begin{tabular}{|c|c|c|}
\hline \multicolumn{3}{|c|}{ Post partum hemorrhage $(n=938)$} \\
\hline Parameter & $\begin{array}{l}\text { Those who undergo Hayman suture } \\
\text { for uterine atony }(n=43) \text { (Percentage) }\end{array}$ & $\begin{array}{l}\text { Those who undergo other method } \\
\text { for uterine atony (n=895) (Percentage) }\end{array}$ \\
\hline \multicolumn{3}{|l|}{ Age } \\
\hline$<20$ years & $2(4.65 \%)$ & $102(11.42 \%)$ \\
\hline 20 to 25 years & $28(65.12 \%)$ & $641(71.65 \%)$ \\
\hline 26-30 years & $8(18.60 \%)$ & $62(6.98 \%)$ \\
\hline$>30$ years & $5(11.63 \%)$ & $89(9.95 \%)$ \\
\hline \multicolumn{3}{|l|}{ Parity } \\
\hline Primi gravida & $2(3.62 \%)$ & $74(8.23 \%)$ \\
\hline Second gravida & $30(69.75 \%)$ & $559(62.41 \%)$ \\
\hline Third gravida & $4(8.68 \%)$ & $130(14.48 \%)$ \\
\hline More than three gravida & $8(17.95 \%)$ & $133(14.88 \%)$ \\
\hline \multicolumn{3}{|l|}{ Period of gestation } \\
\hline Term & $35(81.4 \%)$ & $801(89.46 \%)$ \\
\hline Pre-term & $8(18.6 \%)$ & $94(10.54 \%)$ \\
\hline \multicolumn{3}{|l|}{ Mode of delivery } \\
\hline Lower Segment Cesarean Section & $34(79.07 \%)$ & $204(22.84 \%)$ \\
\hline Vaginal delivery & $9(20.93 \%)$ & $691(77.16 \%)$ \\
\hline \multicolumn{3}{|l|}{ Place of delivery } \\
\hline Primary cases delivered in SMIMER & $38(88.37 \%)$ & $804(89.84 \%)$ \\
\hline Referred from outside & $5(11.63 \%)$ & $91(10.16 \%)$ \\
\hline
\end{tabular}

Table 3. Follow up of patient's with Hayman suture

\begin{tabular}{lcc}
\hline Period offollow-up & Number $(n=43)$ & Percentage \\
\hline Followed-up to seven days & 43 & $100 \%$ \\
Followed-up to six weeks & 30 & $69.77 \%$ \\
Followed-up to six months & 28 & $65.12 \%$ \\
Women coming with subsequent pregnancy at the Institute & 14 & $32.56 \%$ \\
Women with subsequent pregnancy for regular ante-natal care at the Institute & 10 & $23.26 \%$ \\
Women with subsequent pregnancy delivered at the Institute & 5 & $11.63 \%$ \\
\hline
\end{tabular}


All the 43 cases in the study had evidence of uterine atony which responded poorly to conventional uterotonics. Bleeding was controlled in all the cases with Hayman sutures thus averting hysterectomy. Also, the entire patient's up to their respective follow-up period, had an uneventful postoperative recovery except in one referred case, in whom bleeding was controlled with Hayman sutures but later she developed septicemia plus Acute Respiratory Distress Syndrome (ARDS) and died on 21st postpartum day.

\section{Discussion}

Christopher B-Lynch's original case series of five patients underwent the B-Lynch's procedure for massive $\mathrm{PPH}$ as conventional uterotonic agents proved ineffective 5 . In 2002, Hayman placed two vertical sutures on each side of the fundus of the uterus in three patients with $\mathrm{PPH}$ without performing a hysterotomy ${ }^{8}$. The procedure was successful in preserving the uterus and hence fertility. Although uterine atony is often the indication for the use of the compression sutures, it has been shown in many case reports that the suture is also useful in controlling bleeding in cases of placenta previa and placenta accrete $^{8}$.

There have been isolated reports of adverse consequences after B-Lynch application. In 2004, Grotegut et al reported one case of erosion of a B-Lynch suture through the uterine wall, in a 19 year old primigravida ${ }^{9}$. Partial ischemic necrosis of the uterus occurring 24 hours after the procedure has also been reported in a 26-year old primi gravida who underwent an emergency caesarean section for fetal distress followed by B-Lynch suture ${ }^{10}$. The effect of the erosion on future fertility and labor remains unknown. Despite this, many patients on long term follow up have demonstrated resumption of normal menstrual periods and normal reproductive health ${ }^{11}$.

Long term complications such as formation of bowel adhesion have also been reported ${ }^{8}$. Comparing B-Lynch suture with Hayman suture, B-Lynch is time consuming and there is bleeding from uterus due to multiple bites. Uterine opening is avoided with Hayman suture. Cervical stenosis, haematometra, partial necrosis and sloughing of uterine wall have been documented by various surgeons as a complication of original B-Lynch suture technique. Since modified B-Lynch brace sutures is a newer technique, and most of the studies are based on case reports and are without proper controlled studies, more controlled studies are required before it is accepted as a standard method ${ }^{7}$.
In our series, none of the patients had any known adverse outcome till date, except one patient died on 21st post partum day due to ARDS and septicemia and bleeding was also controlled in all without any incidence of secondary PPH and need of hysterectomy. Another study by Ghodke et al, 2008 have reported no mortality after B-Lynch suture but minor complications like fever (5 out of 31) and wound gap (3 out of 31) was reported, though the period of followup was not specified in the study ${ }^{11}$. Study by Fatima N et al, 2010 from Pakistan for effectiveness of combine B-Lynch brace suture plus uterine packing in $\mathrm{PPH}$ in 22 cases reported zero infection rate and two (9.1\%) cases of secondary PPH requiring Hysterectomy ${ }^{12}$. One more study from Pakistan also showed failure rate of $6.6 \%$ (1 out of 15 needing hysterectomy) with B-Lynch suture technique ${ }^{13}$.

Our series of 43 patients illustrate the usefulness of the Hayman procedure in the management of intractable PPH, thus avoiding hysterectomy. Till date we have no further data of continued fertility in patients whose uterus was preserved. There is no randomized controlled data comparing Hayman procedure to other methods of haemostasis for $\mathrm{PPH}$, and it is unlikely that such data would ever be forthcoming, given that $\mathrm{PPH}$ is often unanticipated and occurs under urgent or life threatening situations, thereby rendering randomization and the process of controlling for variables extremely difficult, if not impossible to implement, and also ethically questionable ${ }^{14}$.

\section{Conclusion}

Our initial series of cases of atonic PPH treated with Hayman procedure shows that it is an effective method of controlling PPH. It should be attempted as early as possible in order to maximize its success and prophylactic application should be considered in patients at high risk. Application of a Hayman sutures should be taught to all trainees and registrars in obstetrics. Its relative simplicity and ease of application, its life saving potential, relative safety, and above all, its capacity for preserving the uterus, makes it the recommended procedure of choice if conservative measures do not control PPH; and should be attempted before any radical surgery is considered. It does not require any extra skill and even a resident doctor or a junior doctor can perform it.

\section{Limitation of study}

Retrospective study of this nature is unable to verify the blood loss pre and post procedure. The blood loss of $500 \mathrm{ml}$ or more to diagnose PPH was based on visual inspection which is a subjective and critically 
challenged judgment for validity. Another limitation is that out of 43 total women, only 33 (Attrition rate of $23.26 \%$ ) were traced up to 6 weeks and only 28 (Attrition rate of $34.88 \%$ ) could be traced up to 6 months. Thus loss to follow up was quite high and their outcome pertaining to long term complications and fertility could not be traced.

\section{References}

1. Drife J .Management of primary postpartum hemorrhage. BJOG 1997; 104: 275-7.

2. Coombs CA, Murphy EI, Laros RK. Factors associated with postpartum hemorrhage with vaginal birth. Obst et Gynecol 1991; 77: 69-76.

3. Kaurtz AM, Hugues JM, Grinies DA, et al. Causes of maternal mortality in United States. Obstet Gynecol 1985; 65: $605-82$.

4. Koh E, Devendra K, Tan LK. B-Lynch suture for the treatment of uterine atony. Singapore Med J 2009; 50(7): 693-69

5. B-Lynch C, Coker A, Lawal AH, AbuJ, CowenMJ. The BLynch surgical technique for control of massive postpartum hemorrhage: an alternative to hysterectomy? Five cases reported. Br j Obstet Gynaecol 1997; 104: 372-5.

6. Ghezzi F, Cromi A, Uccella S,Raio L, Bolis P, Surbek D. The Hayman technique: a simple method to treat postpartum hemorrhage. BJOG 2007; 114: 362-5.
7. Ghodake VB, Pandit SN, Umbardand SM.Role of modified B-Lynch suture in modern day management of atonic post partum hemorrhage. JOGC Bombay Hospital Journal, 2008; 50: 206- 207.

8. Hayman RG, Arulkumaran S, Steer PJ. Uterine compression sutures; surgical management of postpartum hemorrhage. Obstet Gynaecol 2002; 99: 2-6.

9. Grotegut CA, Larsen FW, Jones MR, Livingston E. Erosion of a B-Lynch suture through the uterine wall: a case report. J Reprod Med 2004; 49: 849-52.

10. Joshi MV, Shrivastava M. Partial ischaemic necrosis of the uterus following a uterine brace compression suture. BJOG 2004; 111: 279-80.

11. Ghodake V, Pandit S, Umbardand S. Role of modified BLynch suture in Morden day management of atonic postpartum hemorrhage. Bombay Hospital Journal 2008; 50(2): 205-211.

12. Fatima N, Yasmin S, Sadaf J. Combined use of B-Lynch Brace suture and uterine packing in primary post partum hemorrhage: Saving life and fertility. Journal of Surgery Pakistan (International) 2010; 15(3): 144-146.

13. Khatoon A, Hasnny SF, Ansari J. B-Lynch Brace sutures for the treatment of major primary post partum hemorrhage: An experience at Abbasi Shaheed Hospital, Karanchi. Medical Channel 2011; 17(3): 36-38.

14. Wohlmuth CT, Gumbs J, Quebral-Ivie. B-Lynch sutures a case series. Int Fertil Womens Med 2005; 50: 164-73. 